\title{
The Relaxation Behavior of High Chromium- Ni Base Superalloys
}

\author{
Mohamed Nazmy ${ }^{a}$ and Claus Gerdes ${ }^{b}$ \\ Alstom Power Ltd. Baden, $\mathrm{CH}-5401$ \\ amohamed.nazmy@power.alstom.com \\ bclaus.gerdes@power.alstom.com
}

\section{Keywords: Superalloys, Relaxation, $\mathrm{Ni}_{2} \mathrm{Cr}$ intermetallic, Negative creep}

\begin{abstract}
The relaxation behavior of wrought high chromium Ni-base alloys Nimonic 80A, Nimonic 101 and Nimonic 105 was studied at different temperatures. All of these alloys exhibited increase in the residual stress during the relaxation tests e.g. at $450^{\circ} \mathrm{C}$ for Nimonic $80 \mathrm{~A}$ and $650^{\circ} \mathrm{C}$ for Nimonic 105. The observed increase in the residual stress is a manifestation of the known phenomenon of "negative creep". The stress free aging of specimens of these alloys exhibited dimensional contraction at different temperatures ranging from $450^{\circ} \mathrm{C}$ to $650^{\circ} \mathrm{C}$. The abnormal relaxation behavior of these alloys and the observed contraction were attributed to the precipitation and ordering of the intermetallic phase $\mathrm{Ni}_{2}(\mathrm{Cr}, \mathrm{Mo})$ at the test temperature. The differential thermal analysis i.e. DTA results, demonstrated endothermic peaks to correspond with the order-disorder reaction of $\mathrm{Ni}_{2}(\mathrm{Cr}, \mathrm{Mo})$.
\end{abstract}

\section{Introduction}

High chromium Ni-base wrought superalloys such as Nimonic 80A, Nimonic 101 and Nimonic 105 have found extensive use in turbo-machinery applications due to their high strength and corrosion resistance [1-3]. The main strengthening phase in these superalloys is $\gamma^{\prime} \mathrm{Ni}_{3}(\mathrm{Al}, \mathrm{Ti})$ [3]. Another group of high chromium nickel alloys consists of Hastelloy C-276, Hastelloy C-22HS, Nimonic 75, IN617, IN625, IN686 and Haynes 242, is being used in different components in the power generation industries. The precipitation of intermetallic phases occurs either during aging treatments, or during longtime service. The intermetallic of interest in the high chromium superalloys and nickel-molybdenum alloys is $\mathrm{Ni}_{2}(\mathrm{Cr}, \mathrm{Mo})$. This intermetallic is a long-range-order i.e. LRO body centered orthorhombic of the $\mathrm{Pt}_{2} \mathrm{Mo}$ type of structure [4]. It has been reported that the binary $\mathrm{Ni}_{2}(\mathrm{Cr})$ experiences a disorder-order transformation accompanied by lattice contraction at ca $590^{\circ} \mathrm{C}$ [5]. Nevertheless, the critical temperature i.e. $\mathrm{T}_{\mathrm{c}}$ of the order-disorder transformation of the intermetallic $\mathrm{Ni}_{2}(\mathrm{Cr}, \mathrm{Mo})$ depends on the chemical composition of the alloy [6].The ordering of this phase gives rise to:- (a) dimensional instability resulting in "negative creep" and (b) changes in the mechanical properties due to increased resistance to dislocations movement.

The aim of the present investigation is:- studying the relaxation behavior, at intermediate temperatures, of the following alloys;- Nimonic 101, Nimonic 105 and Nimonic 80A, and correlate such behavior to the ordering of the $\mathrm{Ni}_{2}(\mathrm{Cr}, \mathrm{Mo})$ intermetallic phase.

\section{Materials and Experimental Procedure}

The materials used in this investigation were acquired in the form of round bars. Table I gives the nominal composition of the tested alloys and the corresponding heat treatment. The relaxation tests were carried out at a constant total strain $\varepsilon_{t}=0.18 \%$. The corresponding residual stress was continuously recorded during the whole duration of the test. Stress free aging experiments were carried out using round specimens of the different alloys, at different temperatures. The specimen dimensions were measured, at different periods, and the corresponding contraction was calculated. 


\section{Results and Discussion}

The stress relaxation of a specimen of a high chromium $\mathrm{Ni}$-alloy, susceptible to form the $\mathrm{Ni}_{2} \mathrm{Cr}$, is determined by two processes. The first one is the gradual conversion of the elastic strain $\varepsilon_{\text {el. }}$ into plastic strain $\varepsilon_{\text {pl., }}$ by a creep mechanism as expressed in the following equation:

$\varepsilon_{\mathrm{el} .}+\varepsilon_{\mathrm{pl} .}=$ constant.

The second process is the precipitation and ordering of the intermetallic $\mathrm{Ni}_{2} \mathrm{Cr}_{\text {or }} \mathrm{Ni}_{2}(\mathrm{Cr}, \mathrm{Mo})$ that causes the constrained specimen to contract which results in stress increase. These two opposing processes determine the observed relaxation behavior. The stress increase during the relaxation test is a manifestation of the phenomenon of "negative creep".

The results of the relaxation behavior, at different temperatures, of Nimonic 80A, Nimonic 101 and Nimonic 105 are shown in Figures 1, 2, and 3, respectively. Figure 4, gives the results on aging, at different temperatures, of the three alloys of interest.

The residual stress of Nimonic 80A, as given in Fig. 1, exhibited a clear increase as a function of time in the case of at $450^{\circ} \mathrm{C}$ and normal stress relaxation trend at $600^{\circ} \mathrm{C}$ and $650^{\circ} \mathrm{C}$. Nimonic $80 \mathrm{~A}$ exhibited a significant contraction at $450^{\circ} \mathrm{C}$ as shown in Fig. 4. This contraction is due to the formation and ordering of $\mathrm{Ni}_{2} \mathrm{Cr}$. These results agreed very well with what was reported in ref. 8 . The amount of contraction in Nimonic 80A depends on the aging temperature and time [8].

In the case of Nimonic 101, the residual stress exhibited a significant increase with test duration at $650^{\circ} \mathrm{C}$ and normal decrease in stress relaxation at $700^{\circ} \mathrm{C}$, as shown Fig. 2. Nevertheless, the residual stress at $600^{\circ} \mathrm{C}$ exhibited a small dip at the beginning of the test followed by moderate stress increase. This is due to the enhancing effect of stress and temperature on the kinetics of ordering of $\mathrm{Ni}_{2}(\mathrm{Cr}, \mathrm{Mo})$ intermetallic as reported in ref. 9 for the high chromium and molybdenum IN686 alloy. The contraction of Nimonic 101 on aging at $500^{\circ} \mathrm{C}$ and $600^{\circ} \mathrm{C}$ is shown in Fig. 4 and is attributed to the precipitation and ordering of the intermetallic $\mathrm{Ni}_{2}(\mathrm{Cr}, \mathrm{Mo})$. The contraction of the solution treated and water quenched Nimonic 101 specimen is given in Fig.4 as well. The contraction in this specimen is significantly larger than that of the specimens in the fully heat treated condition, since this contraction is due to the precipitation of both $\gamma^{\prime}$ i.e. $\mathrm{Ni}_{3}(\mathrm{Al}, \mathrm{Ti})$ and the ordering of $\mathrm{Ni}_{2}(\mathrm{Cr}, \mathrm{Mo})$. The DTA curve on Fig. 5, shows an endothermic peak at ca $660^{\circ} \mathrm{C}$, of an aged Nimonic 101 specimen, due to the order- disorder reaction in this alloy.

The relaxation behaviors of Nimonic 105 at $650^{\circ} \mathrm{C}$ and $700^{\circ} \mathrm{C}$ are given in Fig. 3. The residual stress exhibited an increase during the test at $650^{\circ} \mathrm{C}$. This is again due to the precipitation of the LRO $\mathrm{Ni}_{2}(\mathrm{Cr}, \mathrm{Mo})$ and further precipitation of $\gamma^{\prime}$ particles. At $700^{\circ} \mathrm{C}$ test, the residual stress showed an increase followed by a gradual decrease. This behavior could be due to the slow disordering of the $\mathrm{Ni}_{2}(\mathrm{Cr}, \mathrm{Mo})$ phase in this alloy, and the increase in the creep strain at $700^{\circ} \mathrm{C}$. According to ref. 6 the $\mathrm{T}_{\mathrm{c}}$ of the intermetallic phase in a certain alloy depends on the chemical composition of that alloy. Specimens of $\mathrm{Ni}_{2} \mathrm{Cr} \& \mathrm{Ni}_{2}(\mathrm{Mo}, \mathrm{Cr})$ intermetallic phases were prepared by button arc melting for DTA investigations. Fig. 5 shows the DTA results of aged Nimonic 101, and the stoichiometric intermetallics $\mathrm{Ni}_{2} \mathrm{Cr}$ and $\mathrm{Ni}_{2}(\mathrm{Cr}, \mathrm{Mo})$. The result on contraction of Nimonic 105 is given in Fig. 4 . 


\section{Conclusions}

(1) Nimonic 80A, Nimonic 101 and Nimonic 105 alloys exhibited increase in the residual stress during relaxation testing at different temperatures as a manifestation of "negative creep".

(2) The same alloys exhibited dimensional contraction during stress free aging at different temperatures due to the precipitation and ordering of the intermetallic phase $\mathrm{Ni}_{2}(\mathrm{Cr}, \mathrm{Mo})$.

(3) The DTA results showed endothermic peak at ca $650^{\circ} \mathrm{C}$ to correspond with the orderdisorder reaction of the intermetallic phase.

(4) The observed unusual relaxation behaviors, at different temperatures, of the high chromium Ni base superalloys i.e. Nimonic 80A, Nimonic 101 and Nimonic 105 should be taken into consideration on designing components e.g. bolts \& springs for high temperature applications.

\section{Acknowledgement}

The authors would like to express their appreciation to A.Künzler for his diligent technical assistance during the course of the present investigation.

\section{References}

[1] K.H.Mayer and K.H.Keinburg, "Operating Experience and Life Span of Heat-Resistant Bolted Joints in Steam Turbines of Fossil-Fired Power Stations”, in I Mech. E., C221/80, 1980.

[2] M.S.Loveday and B.F.Dyson, "Prestrain-Induced Particle Microcracking and Creep Cavitation IN 597”, in Acta Metall. Vol. 31. No 3,pp 397-405, 1983.

[3] E.Metcalfe, B. Nath and A. Wickens, " Some Effects of the Ordering Transformation in Nimonic 80A on Stress Relaxation Behaviour", in Materials Science and Engineering, 67, pp. 157-162, 1984.

[4] H.M.Tawancy, "Order-Strengthening in a Nickel-Base Superalloy (Haselloy Alloy S)", in Metall. Trans.A Vol. 11A, pp.1764-1765, 1980.

[5] A.Marucco and B.Nath, "Effect of ordering on the properties of Ni-Cr alloys", in Journal of Materials Science 23, pp.2107-2114, 1988.

[6] D.Blavette, E.Cadel and B.Deconihout,"The Role of the Atom Probe in the Study of Nickel-Based Superalloys", in Materials Characterization 44, pp.133-157, 2000.

[7] E.Lang, V.Lupinc and A Marucco, "Effect of Thermomechanical Treatments on Shortrange Ordering and Secondary-phase Precipitation in Ni-Cr based Alloys", in Materials Science and Engineering, A114, pp.147-157, 1989.

[8] A.Marucco, "Effect of Composition on The Order-Disorder Transformation in Ni-Cr Based Alloys", in Key Engineering Materials Vols.48, pp.77-90, 1990.

[9] Kaori Miyata, "Effect of Hydrogen Charging on Dislocation Behavior in $\mathrm{Ni}-\mathrm{Cr}$ and $\mathrm{Ni}_{2} \mathrm{Cr}$ Alloys", in Metall. Trans. A 34A, pp.1249-1257, 2003. 
Table1: Chemical composition in wt \% and heat treatment of Ni-base alloys \& superalloys

\begin{tabular}{|l|c|c|c|c|c|c|c|c|c|c|c|c|c|}
\hline Alloy & $\mathbf{N i}$ & $\mathbf{C r}$ & $\mathbf{C o}$ & $\mathbf{M o}$ & $\mathbf{W}$ & $\mathbf{T a}$ & $\mathbf{N b}$ & $\mathbf{A l}$ & $\mathbf{T i}$ & $\mathbf{F e}$ & $\mathbf{M n}$ & $\mathbf{S i}$ & $\mathbf{C}$ \\
\hline Nimonic80A & 76 & 19,5 & - & - & - & - & - & 1,4 & 2,4 & - & 0,3 & 0,3 & 0,06 \\
\hline Nimonic101 & 48 & 24,5 & 10 & 10 & - & - & 1 & 1,5 & 3 & - & - & - & 0,05 \\
\hline Nimonic105 & 53 & 15 & 20 & 5 & - & - & - & 4,7 & 1,2 & - & 0,3 & 0,3 & 0,13 \\
\hline
\end{tabular}

Nimonic 80A: $1080^{\circ} \mathrm{C} / 8 \mathrm{~h} / \mathrm{AC}+705^{\circ} \mathrm{C} / 16 \mathrm{~h} / \mathrm{AC}$

Nimonic 101: $1100^{\circ} \mathrm{C} / 4 \mathrm{~h} / \mathrm{AC}+850^{\circ} \mathrm{C} / 16 \mathrm{~h} / \mathrm{AC}$

Nimonic 105: $1150^{\circ} \mathrm{C} / 4 \mathrm{~h} / \mathrm{AC}+1050^{\circ} \mathrm{C} / 16 \mathrm{~h} / \mathrm{AC}+850^{\circ} \mathrm{C} / 16 \mathrm{~h} / \mathrm{AC}$

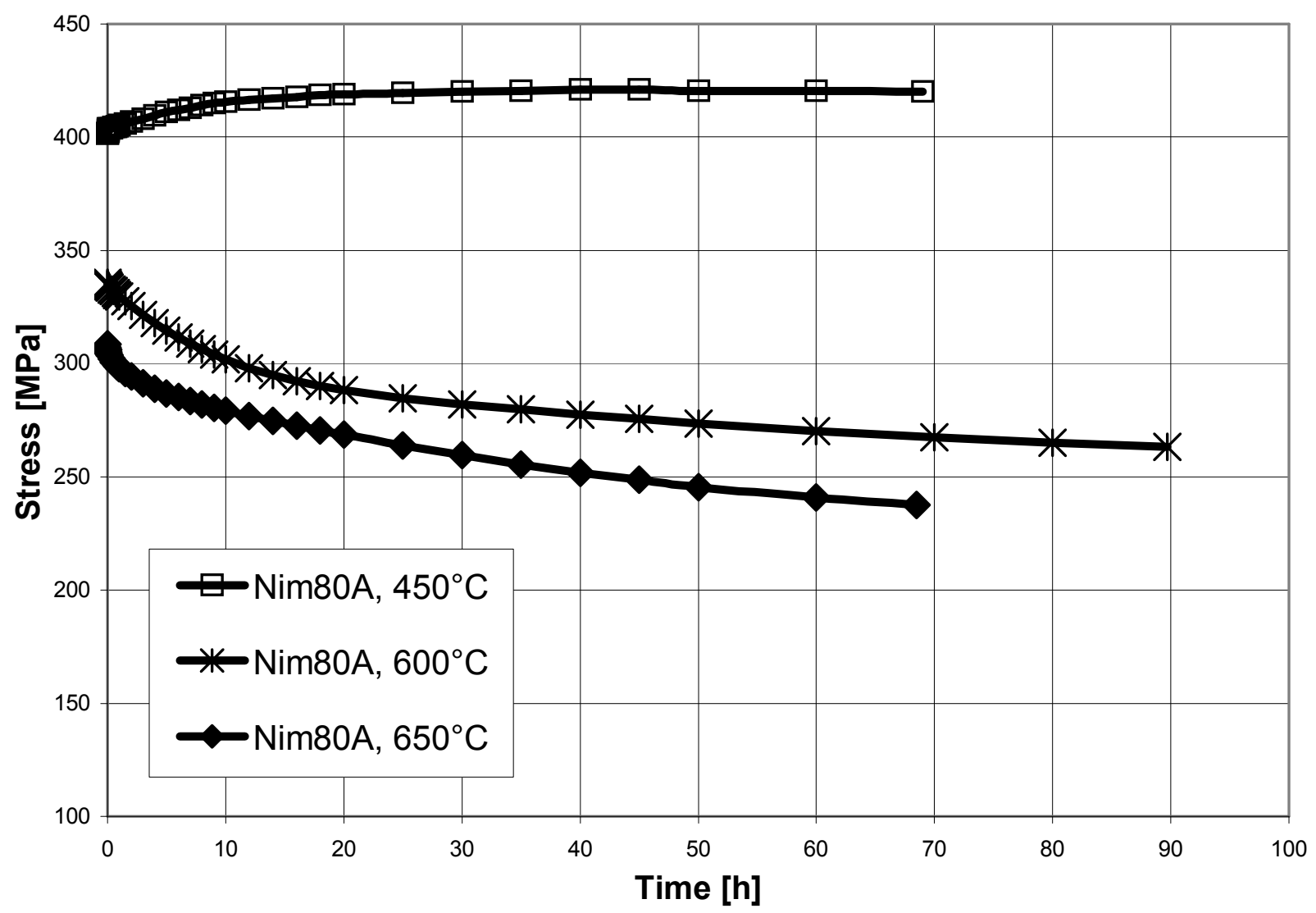

Fig. 1: Relaxation behavior of Nimonic $80 \mathrm{~A}, \varepsilon_{\mathrm{t}}=0.18 \%$ 


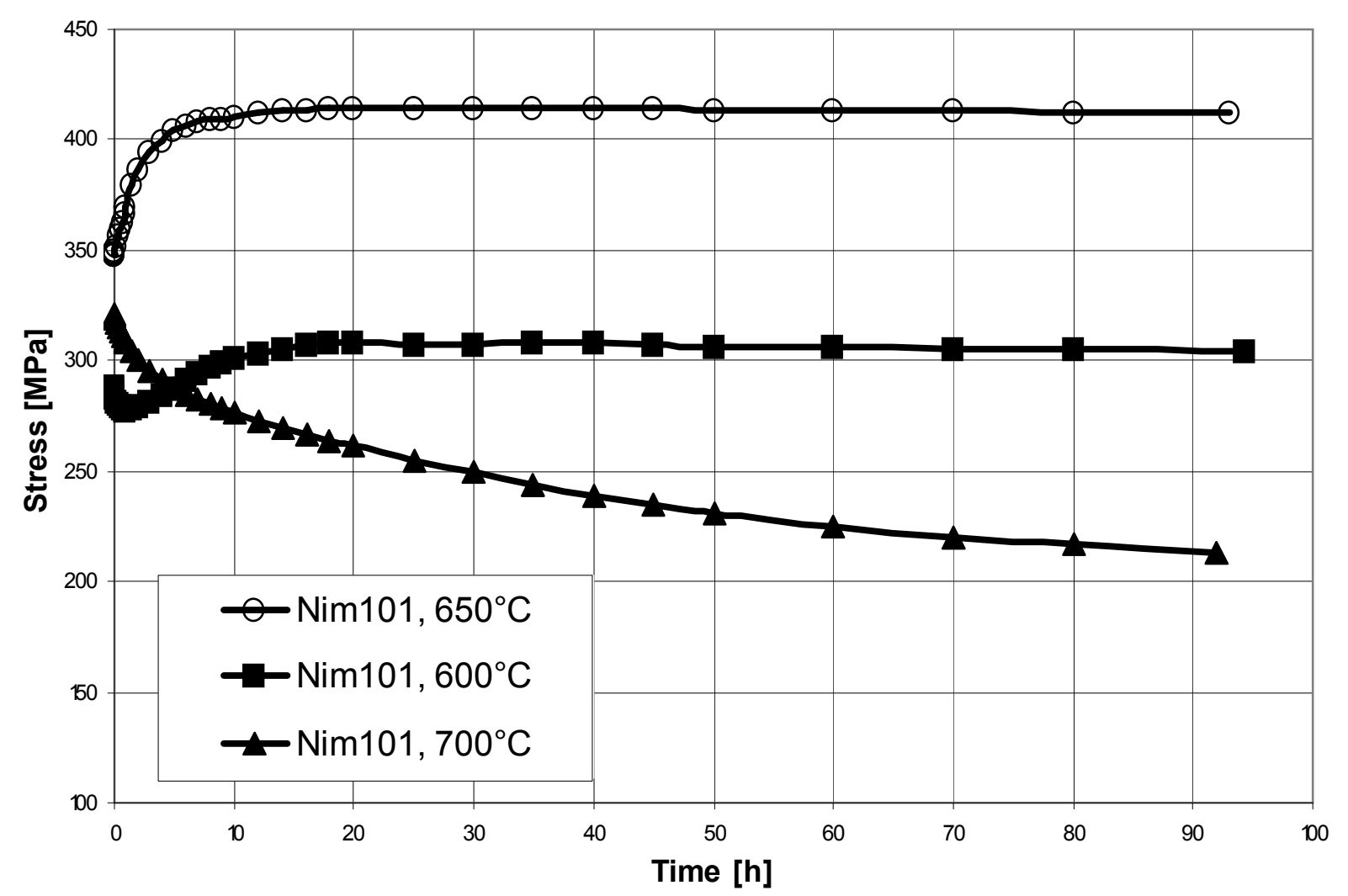

Fig. 2: Relaxation behavior of Nimonic 101, $\varepsilon_{\mathrm{t}}=0.18 \%$

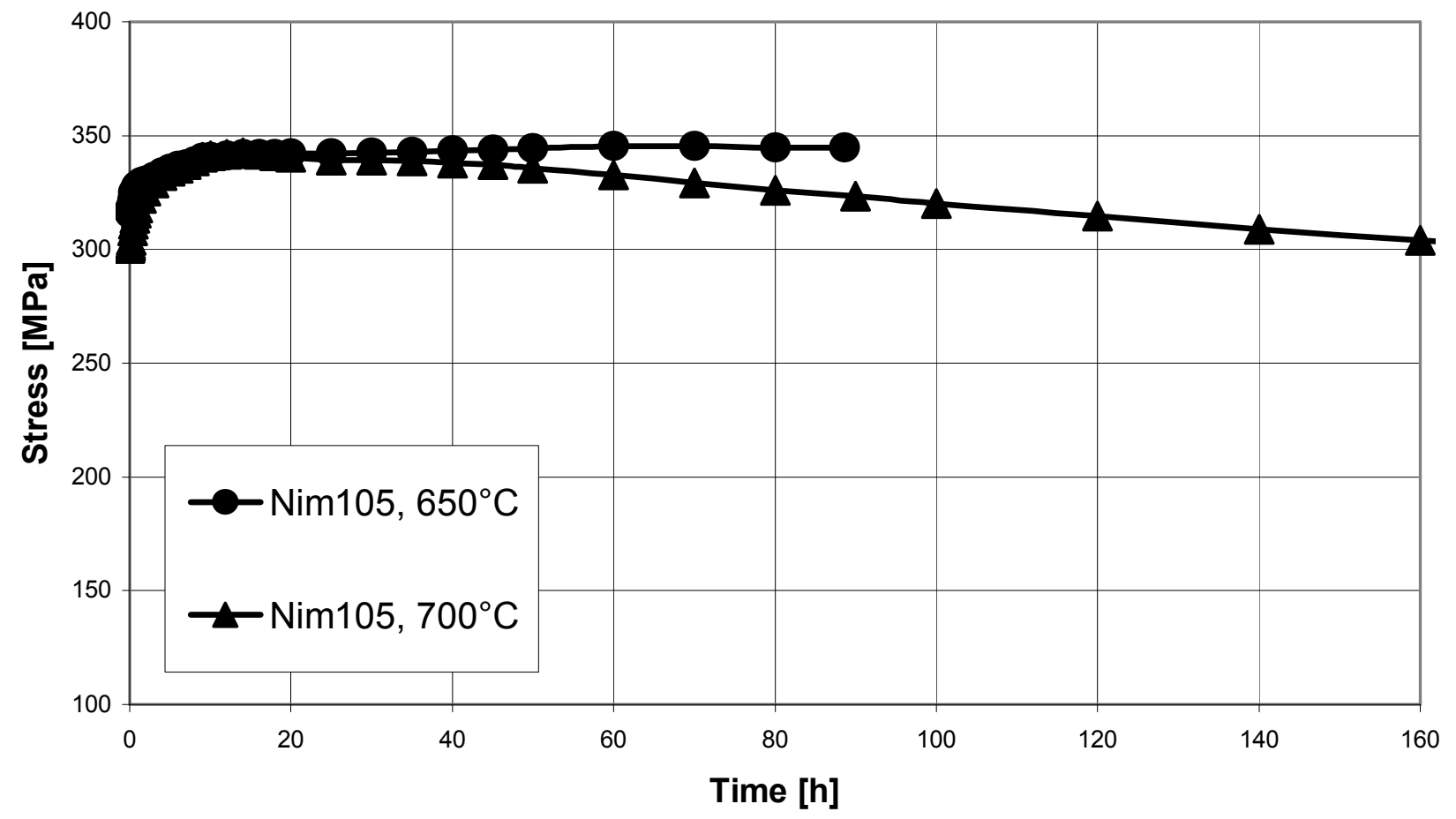

Fig. 3: Relaxation behavior of Nimonic $105, \varepsilon_{t}=0.18 \%$ 


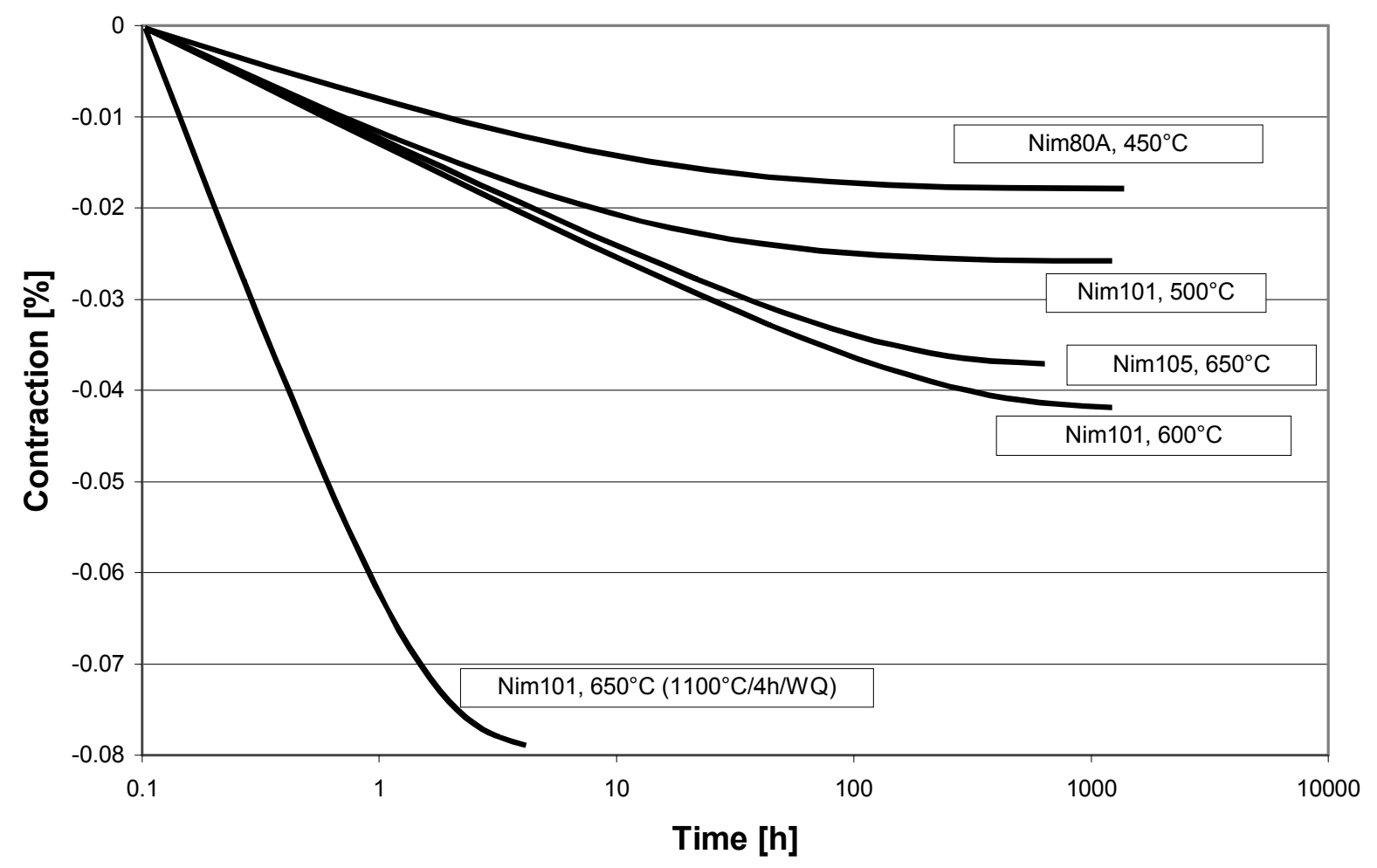

Fig. 4: Dimensional contraction of Ni-base alloys at different temperatures

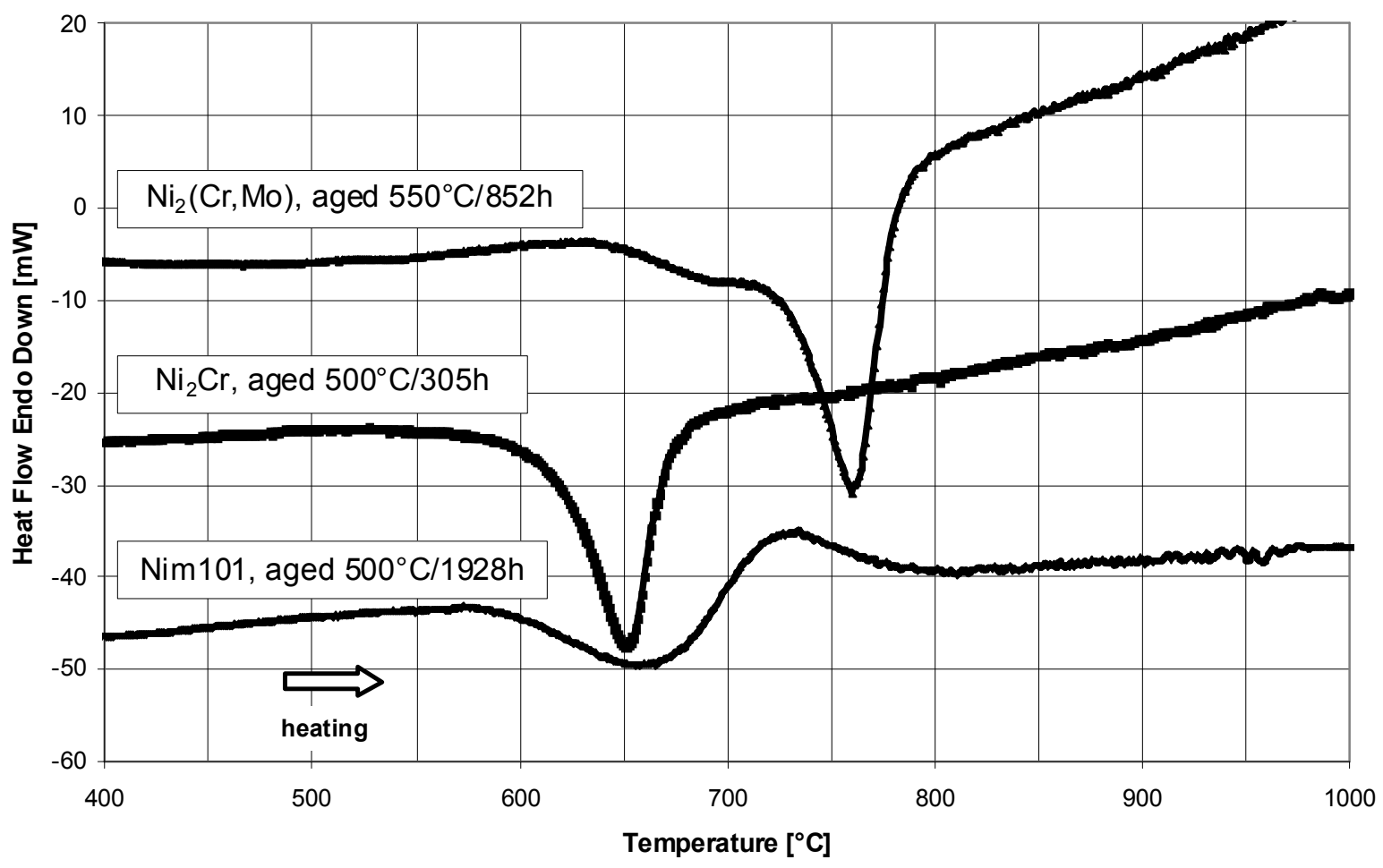

Fig. 5: DTA curve of aged Nimonic $101, \mathrm{Ni}_{2} \mathrm{Cr}$ and $\mathrm{Ni}_{2}(\mathrm{Cr}, \mathrm{Mo})$ 